\title{
Multimodal imaging in radioguided surgery
}

\author{
G. H. KleinJan · A. Bunschoten • O. R. Brouwer • \\ N. S. van den Berg $\cdot$ R. A. Valdés-Olmos • \\ F. W. B. van Leeuwen
}

Received: 31 July 2013/Accepted: 8 November 2013/Published online: 4 December 2013

(C) Italian Association of Nuclear Medicine and Molecular Imaging 2013

\begin{abstract}
Radioguided surgery (RGS) utilizes radiolabeled tracers that accumulate in the lesion of interest following local or systemic administration. RGS is an expanding surgical guidance technology, but unfortunately most currently available radiotracers are unable to provide intraoperative optical information regarding the location of the lesion. In 2011, a new hybrid tracer (both radioactive and fluorescent) was introduced for sentinel lymph node detection. This hybrid tracer (indocyanine green $-{ }^{99 \mathrm{~m}} \mathrm{Tc}$ nanocolloid) has helped to generate a new hybrid surgical guidance concept, thereby expanding the traditional RGSbased approach. Based on its radioactive signature a hybrid tracer is able to preserve the "traditional" role for RGS. Furthermore, as an additional tool in the operating room, a hybrid tracer provides optical information via fluorescence guidance. This review discusses the most common RGS approaches. Different clinically used radioactive tracers
\end{abstract}

Color figures online at http://link.springer.com/article/10.1007/ s40336-013-0039-6.

G. H. KleinJan · A. Bunschoten · O. R. Brouwer .

N. S. van den Berg · R. A. Valdés-Olmos .

F. W. B. van Leeuwen $(\bowtie)$

Interventional Molecular Imaging Laboratory, Department of Radiology, Leiden University Medical Center, Albinusdreef 2 (C2-S zone), 2300 RC Leiden, The Netherlands

e-mail: f.w.b.van_leeuwen@lumc.nl

G. H. KleinJan · N. S. van den Berg - R. A. Valdés-Olmos Department of Nuclear Medicine, The Netherlands Cancer Institute-Antoni van Leeuwenhoek Hospital, Plesmanlaan 121, 1066 CX Amsterdam, The Netherlands

F. W. B. van Leeuwen

Department of Head and Neck Surgery, The Netherlands Cancer Institute-Antoni van Leeuwenhoek Hospital, Plesmanlaan 121, 1066 CX Amsterdam, The Netherlands and their potential hybrid derivatives are also discussed. Furthermore, the various imaging devices designed for radioactivity-based detection are reviewed in the context of generating hybrid-imaging modalities.

Keywords Radioguided surgery - Fluorescenceguided surgery $\cdot$ Radiotracer $\cdot$ Multimodal ·

Molecular imaging

\section{Introduction}

The goal of radioguided surgery (RGS) is to take advantage of local accumulation of a preoperatively injected radioactive tracer to achieve effective intraoperative localization of a lesion of interest. RGS, allows more complete resections, reducing the need for reoperations (Fig. 1). Both gamma- and beta-emitting radioisotopes can be used for RGS, e.g., fluorine-18 $\left({ }^{18} \mathrm{~F}\right)$, gallium-67 $\left({ }^{67} \mathrm{Ga}\right)$, technetium-99 $\mathrm{m}\left({ }^{99 \mathrm{~m}} \mathrm{Tc}\right)$, indium-111 $\left({ }^{111} \mathrm{In}\right)$ and iodine-125 or iodine-131 $\left({ }^{125} \mathrm{I},{ }^{131} \mathrm{I}\right)$ [1]. With the radiation penetrating deeply through tissue, the influence of tissue attenuation on the detection sensitivity is limited. This beneficial feature also allows the radioactive signal to be used for the acquisition of preoperative (3D) images by means of, for example, single photon emission computed tomography (SPECT) or positron emission tomography (PET). The value of SPECT or PET data further improves when these modalities are supplemented with anatomical detail provided by computed tomography (CT) or magnetic resonance imaging (MRI). To this end, SPECT/CT and PET/ CT were introduced, followed more recently by PET/MRI. The information provided by these combined modalities, depicting the radioactive target lesion(s) within the patient's body, constitutes a useful roadmap for surgeons. 
Fig. 1 Schematic overview of the addition of optical guidance to the conventional radioguided surgery approach.

a Radioguided surgery approach. Following radiotracer injection, preoperative imaging can be performed to localize the lesion of interest.

Intraoperatively, the lesion of interest can then be approached/ localized with a gamma/PET probe and/or via gamma imaging using a portable gamma camera. b With the injection of a fluorescent tracer, e.g., incorporated in a hybrid tracer, intraoperative fluorescence imaging allows visualization of the lesion of interest (color figure online)

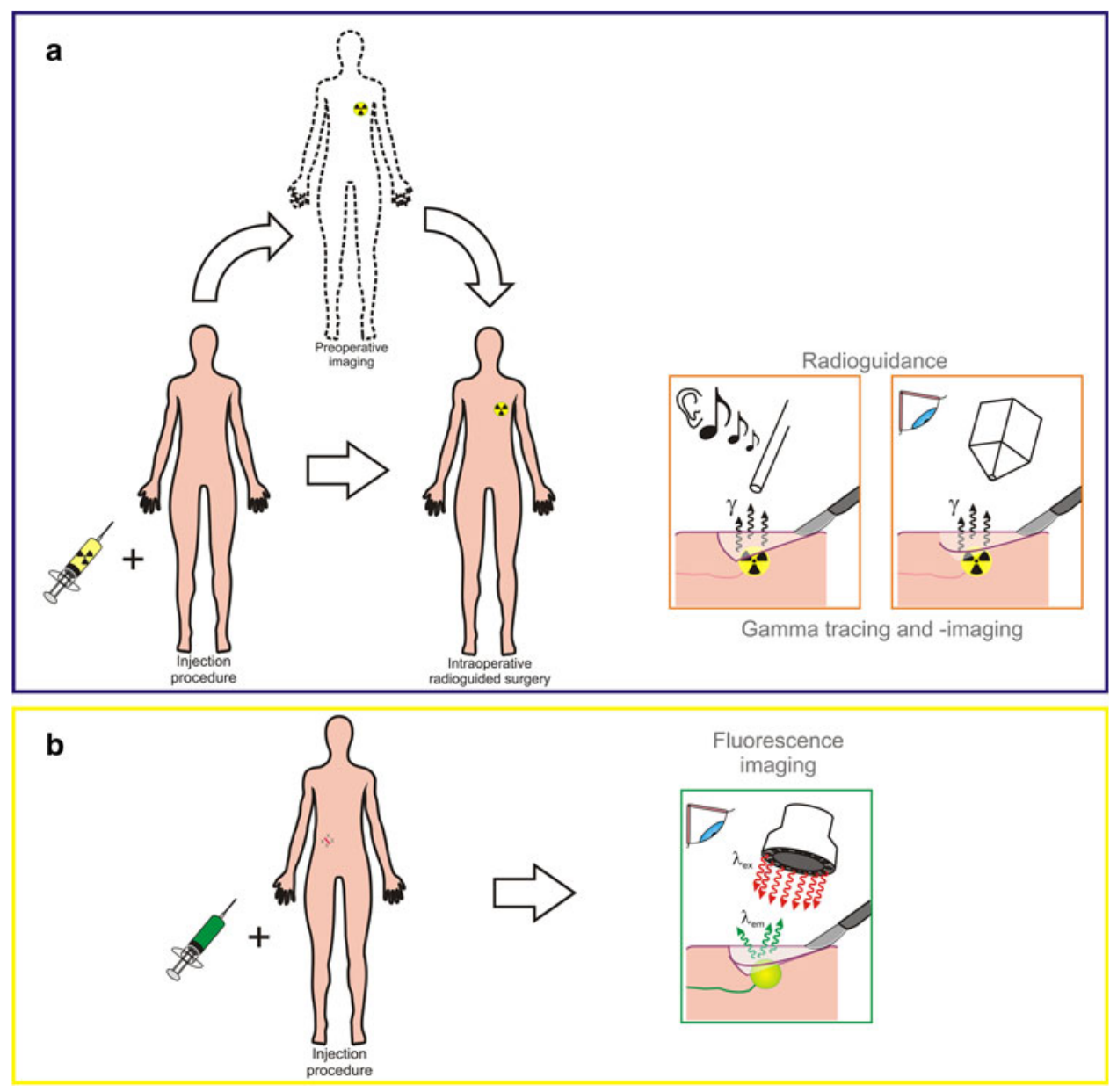

While the radioactive signal allows the surgeon to sensitively locate the area of interest prior to incision, during the operation itself, the limited spatial resolution of the current nuclear modalities may impair resection accuracy. It must be noted that while good spatial resolution can be obtained with SPECT in the preoperative setting $(<0.25 \mathrm{~mm})$, this resolution cannot be obtained intraoperatively with the currently available modalities $[1,2]$. Furthermore, 'signal bleeding' can make it difficult to accurately locate the origin of the radioactive signal during surgery. To compensate for these limitations, there is an increasing need, alongside RGS, for approaches that provide high-resolution (optical) information.

Optical information plays a key role in real-time assessment and surgical decision-making. For example, it allows movement of anatomical structures to be monitored by the surgeon, while dyes can be used to mark an area of interest. The surgical identification of lymph vessels and lymph nodes using vital blue dye (e.g., patent or methylene blue) during radioguided sentinel lymph node (SLN) biopsy is perhaps the best known example of the clinical application of dyes [3, 4]. The use of Cerenkov-emitting PET tracers and/or (near-infrared) fluorescent dyes [e.g., fluorescein, indocyanine green (ICG) or 5-aminolevulinic acid] can further improve the optical detection of lesions $[5,6]$. Since the tissue penetration of a fluorescent dye is dependent on the excitation and emission wavelength of the dye, an increased penetration depth can be achieved by applying near-infrared dyes; ICG, for example, allows optical detection of lesions embedded in up to $1 \mathrm{~cm}$ of tissue. Clearly, the tissue penetration of these optical signals remains limited in comparison to the penetration depth of the above-mentioned radioactive tracers, rendering the nuclear approach indispensable for 3D localization. Preclinical validation was recently followed by the clinical introduction of multimodal (hybrid) tracers that contain both a radioactive and a fluorescent moiety [7, 8], and the potential of these hybrid tracers to enhance conventional RGS technologies with the beneficial properties of optical guidance has already been demonstrated $[9,10]$.

This review discusses the most common RGS approaches. Different clinically used radioactive tracers and their potential hybrid derivatives are also discussed. Furthermore, the various imaging devices designed for radioactivity-based detection are reviewed in the context of generating hybrid-imaging modalities. 


\section{Radioguided surgery techniques}

Radioguided surgery techniques based on intravenous radiotracer administration

\section{Radioguided intraoperative margin evaluation (RIME)}

In RIME, radioactivity is used to check whether the resection margins are negative. Depending on the tumortargeting capabilities of the radiolabeled tracer, accumulation in the tumor, or on its surface, can, during the operation, be detected with a gamma-ray detection probe (hereafter referred to as gamma probe). The acoustic readout of the gamma probe helps to detect the extent of the tumor, and therefore allows more complete surgical removal [11]. If any residual activity is encountered in the resection area, this tissue can then also be excised.

Radio-immuno-guided surgery (RIGS) is a technique applied in tumor localization. It involves the intravenous injection of radiolabeled monoclonal antibodies, or antibody fragments, that target antigens expressed on tumor cells or in the tumor stroma. These radiotracers can be used for both diagnostic imaging and, in a similar way, in RIME, for surgical localization of tumors [12]. For example, carcinoembryonic antigen-specific monoclonal antibody (anti-CEA MoAB) can be used to locate specific tumors, e.g., rectal cancer [13].

Radioguided surgery techniques based on local injection of a radiotracer

\section{Sentinel lymph node biopsy}

The most commonly applied RGS procedure is SLN biopsy [1]. This approach involves local injection of a radiotracer, whose accumulation is used to detect occult lymph node (micro-)metastases at an early stage by means of selective identification, and biopsy of the lymph node(s) directly draining from the primary tumor (the SLN) [4].

The SLN approach was introduced by Morton et al. [3] and became the clinical standard for the staging of clinically lymph node-negative patients. Later, lymphoscintigraphy following a radiocolloid injection was combined with the use of optical blue dye for SLN identification [14]. Most commonly applied for breast cancer and melanoma, this technique has been found to be valuable for lymphatic staging in a variety of cancers [1].

\section{Radioguided seed localization (RSL)}

Radioguided seed localization with a radioactive ${ }^{125}$ I-seed has been introduced as an alternative to the wire-guided localization (WGL) technology. The ${ }^{125} \mathrm{I}$-seed is placed in the tumor center stereotactically or under ultrasound (US) guidance. During surgery, the seed can be localized with a dual-isotope gamma probe, without interfering with, for example, ${ }^{99 \mathrm{~m}}$ Tc-based SLN biopsy.

Radioguided seed localization is also useful in the neoadjuvant setting. Because of the long half-life of the ${ }^{125}$ I-seed (59 days), it can be placed prior to the start of the neoadjuvant chemotherapy while remaining traceable after completion of the chemotherapy regimen [15]. Migration of the seed is rare and high rates of radical excision have been reported both in primary surgery and after neoadjuvant chemotherapy $[15,16]$.

\section{Radioguided occult lesion localization (ROLL)}

Radioguided occult lesion localization, similar to RSL, also provides an alternative to WGL. With this technique, injection of ${ }^{99 \mathrm{~m}} \mathrm{Tc}$-labeled radiocolloid into the tumor is followed by a local excision, guided by the gamma probe. In the neoadjuvant setting, a twist marker is inserted into the tumor before the start of neoadjuvant chemotherapy. After the chemotherapy and prior to surgery, the ${ }^{99 \mathrm{~m}} \mathrm{Tc}$ is inserted next to the marker. High rates of radical resections have been reported with ROLL [17]. ${ }^{99 \mathrm{~m}} \mathrm{Tc}$ has a short halflife $(6 \mathrm{~h})$ and, for this reason, its application in the neoadjuvant setting requires, for ROLL, two interventions before surgery (i.e., insertion of the marker and injection of the radiocolloid); for RSL, on the other hand, only insertion of the ${ }^{125} \mathrm{I}$ seed is required [18]. An advantage of ROLL over RSL is that ROLL can be directly combined with SLN biopsy, resulting in so-called sentinel node occult lesion localization (SNOLL) [19, 20].

\section{Radioguided ultrasound-guided lymph node localization (RULL)}

In RULL, radiocolloid injection is followed by conventional preoperative SLN mapping. This is then combined with US examination of the SLNs to ascertain whether there are metastases present. The positive lymph nodes are marked and then surgically excised. RULL constitutes a possible refinement of the "traditional" SLN biopsy procedure [21].

\section{Radiotracers}

Radiotracers for intravenous administration

\section{Antibodies}

In RIGS, the overexpression of specific biomarkers on tumor cells (or in their stroma) is used to identify areas of disease. Targeting is accomplished using radiolabeled 
monoclonal antibodies or antibody fragments [12]. In colorectal cancer patients, targeting with anti-TAG-72 antibodies was used to detect residual tumor tissue; a poorer survival outcome was found in patients with residual hot spots residual hot spots after resection [22]. This finding suggests that the technique may help optimize radical surgery. Povoski et al. [23] recently applied RIGS in the resection of renal cell carcinoma; the imaging and detection approach used by these authors was based on ${ }^{124} \mathrm{I}$-cG250 ( ${ }^{124}$ I-girentuximab), which targets carbonic anhydrase IX.

In addition to complete antibodies, ${ }^{111}$ In-labeled antibody fragments of trastuzumab have also been used in human epidermal growth factor 2-positive carcinoma of the breast [24]. Unfortunately, in a pilot study of six patients this tracer did not aid in intraoperative tumor localization; the main reason for the detection failure was believed to be the low dose of activity administered (74 MBq).

Although antibodies have a high affinity and specificity for their target antigen, a disadvantage of applying antibodies for RGS is their long circulation time. To obtain sufficient tumorto-background ratios, the unbound antibodies must be allowed to clear [13]. With antibody fragments, this unbound antibody clearance should be faster, making it possible to reduce the time elapsing between injection and surgery.

${ }^{123}$ I-iodide and ${ }^{131}$ I-iodide

The standard therapy for thyroid cancer is complete thyroidectomy followed by ${ }^{131}$ I-iodide ablation therapy. The two most important radionuclides for localization of thyroid tissue are ${ }^{123}$ I-iodide and ${ }^{131}$ I-iodide. When performing a complete thyroidectomy, tracing the radioactive iodine may be used to confirm complete resection; iodine is taken up by thyroid tissue and, on the basis of the radioactive signal, can be used to locate residual thyroid tissue after resection [25]. However, a study by Tunca et al. [26] concluded that the RGS approach was not superior to conventional complete thyroidectomy (Fig. 2).

${ }^{99 m}$ Tc-sestamibi $\left({ }^{99 m} T c-M I B I\right)$

Parathyroidectomy with bilateral lymphatic neck dissection is the standard procedure for primary hyperparathyroidism patients [27]. This procedure has very high success rates,

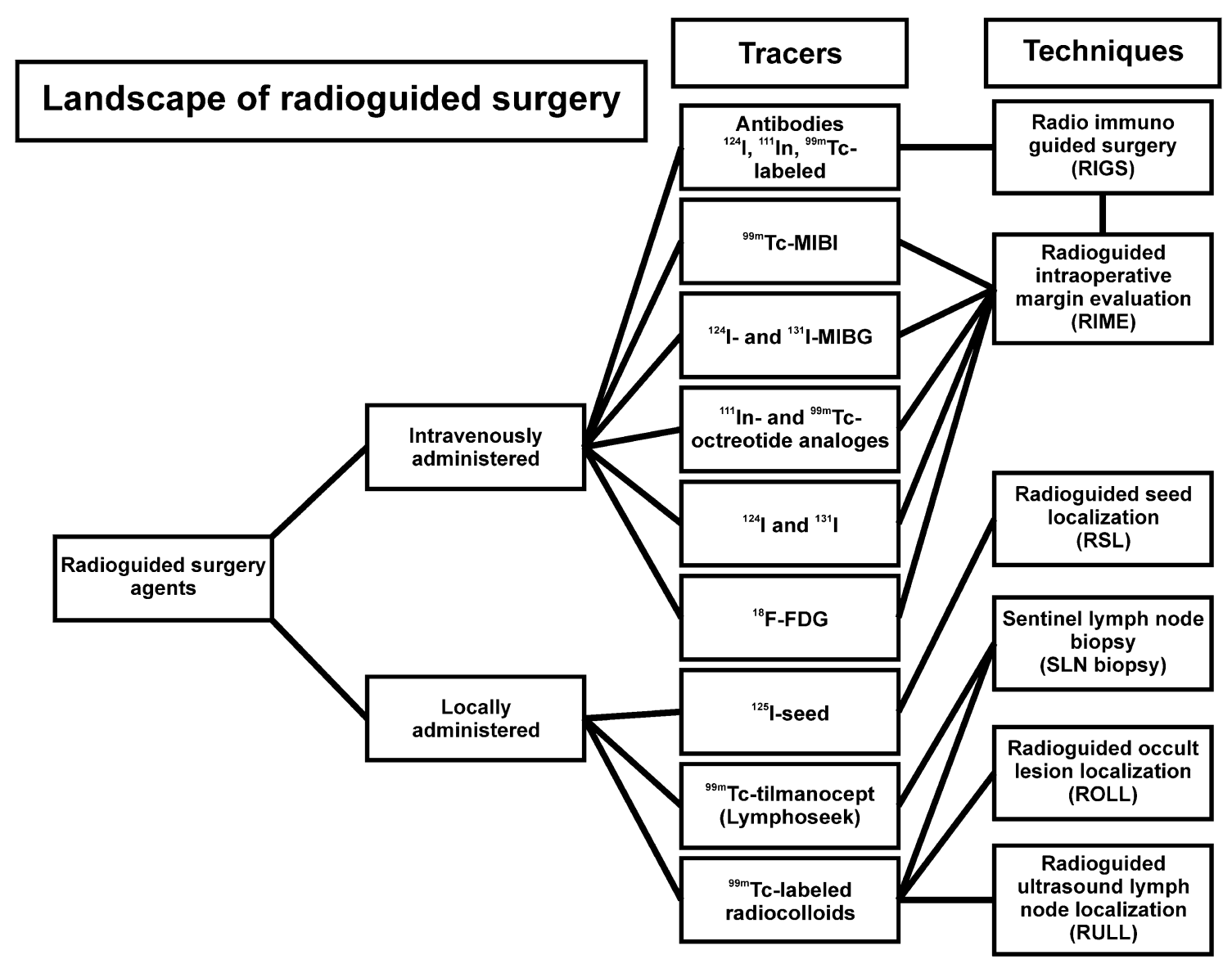

Fig. 2 The landscape of radioguided surgery. ${ }^{124} I$ iodine-124, ${ }^{125} I$ iodine-125, ${ }^{131} I$ iodine-131, ${ }^{111} I n$ indium- $111,{ }^{99 m} T c$ technetium-99m, ${ }^{18} F$ $F D G$ fluorine-18-fluorodeoxyglucose, $M I B G$ meta-iodobenzylguanidine 
but a single residual adenoma can lead to recurrent hyperparathyroidism. Due to its retention in mitochondria, ${ }^{99 \mathrm{~m}}$ Tc-MIBI can be used for preoperative parathyroid identification using scintigraphy and SPECT/CT imaging (Fig. 3) [28]. During surgery, a gamma probe can then be used to localize the ${ }^{99 \mathrm{~m}}$ Tc-MIBI accumulated in adenomas. Similarly, ${ }^{99 \mathrm{~m}}$ Tc-MIBI can also be used for recurrent parathyroid adenomas [29].

${ }^{99 \mathrm{~m}}$ Tc-MIBI has also been used for RGS in iodinenegative recurrent differentiated and medullary thyroid cancer [30]. This agent allowed gamma probe localization and subsequent resection of thyroid tissue that had not shown uptake of ${ }^{123}$ I-iodide or ${ }^{131} \mathrm{I}$-iodide.

${ }^{99 \mathrm{~m}}$ Tc-MIBI scintigraphy can also be used for the detection of breast carcinoma. Its use in a clinical study assessing the RIME technique in breast cancer patients showed a $82.6 \%$ success rate, with a mean tumor free margin of $4.8 \mathrm{~mm}$ [11].

\section{Meta-iodobenzylguanidine (MIBG)}

${ }^{123}$ I- and ${ }^{131}$ I-MIBG (Adreview ${ }^{\circledR}$ ) can be used for the detection/treatment of neuroendocrine tumors (NETs).
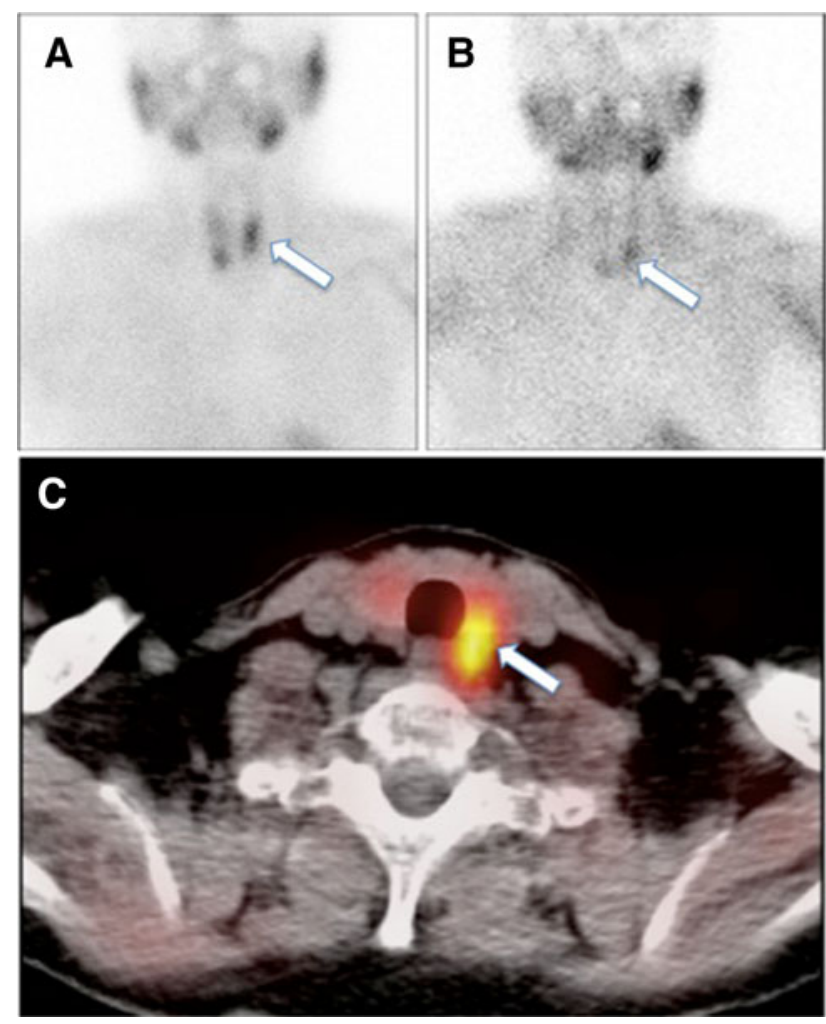

Fig. $3{ }^{99 \mathrm{~m}}$ Tc-MIBI for parathyroid adenoma localization. a ${ }^{99 \mathrm{~m}} \mathrm{Tc}-$ MIBI scintigram showing heterogenous thyroid uptake on the early image with $\mathbf{b}$ retention of the tracer in the left lobe on the $3 \mathrm{~h}$ postinjection image. c SPECT/CT clarifies the abnormal uptake seen in the dorsal area of the left thyroid lobe. During radioguided surgery a parathyroid adenoma was resected (color figure online)
MIBG mimics the structure of noradrenaline and, therefore, targets the noradrenaline transporter. A systematic review by van Hulsteijn et al. [31] discussed the application of MIBG for the intraoperative detection and resection of NETs. They concluded that in specific cases, like small non-palpable tumors or tumors located in adhesive scar tissue, MIBG can be useful for intraoperative detection. However, in some instances somatostatin analogs like ${ }^{111}$ In-pentetreotide may have higher sensitivity than MIBG labeled with iodine for targeting NETs [31].

${ }^{111}$ In- and ${ }^{99 m}$ Tc-octreotate analogs

${ }^{111}$ In-diethylenetriamine penta-acetic (DTPA)-octreotide $\left(\right.$ Octreoscan $\left.^{\circledR}\right),{ }^{99 m}$ Tc-depreotide $\left(\right.$ Neotect $\left.{ }^{\circledR}\right)$ and ${ }^{111}$ Inpentetreotide can be used for the detection of tumors overexpressing the somatostatin receptor [e.g. NETs, (non) small cell lung cancer] (Fig. 4) [32-34]. The highly specific uptake of these compounds in the tumor tissue allowed radioguidance towards the tumor. For example, complete resection of ACTH-secreting bronchial carcinoids was achieved with RGS after injection of ${ }^{111}$ In-pentetreotide [34]. With this tracer, even millimeter-sized tumor nodules and lymph node metastases could be resected.

A big advantage of these receptor-targeted peptides is their good biodistribution and rapid unbound tracer clearance, which results in a good tumor-to-background ratio in a relatively short time (1-24 h). However, their short in vivo half-life does impose strict timing of injection, preoperative imaging, surgical planning and the RGS procedure.

\section{${ }^{18} F-F D G$}

Generally, malignant tumors have an accelerated glucose metabolism, which results in higher uptake of the PET tracer ${ }^{18}$ F-FDG. Due to the high signal-to-background ratios obtained, ${ }^{18}$ F-FDG is considered valuable for imaging tumor diffusion throughout the body in a variety of malignancies [35]. The ability to detect different types of malignancies makes this tracer a possible generic tracer for RGS-based tumor resection [36].

Radiotracers for local administration

\section{Radiocolloids}

The most frequently used radiotracers for RGS, especially for SLN biopsy, are ${ }^{99 \mathrm{~m}}$ Tc-sulfur colloid, ${ }^{99 \mathrm{~m}}$ Tc-colloidal human albumin ( ${ }^{99 \mathrm{~m}} \mathrm{Tc}-$ nanocolloid), ${ }^{99 \mathrm{~m}} \mathrm{Tc}$ antimony trisulfide colloid, and ${ }^{99 \mathrm{~m}}$ Tc-tin colloid $[1,37] .{ }^{99 \mathrm{~m}}$ Tc-labeled radio colloids have been applied mainly in SLN biopsy and ROLL/SNOLL procedures [4, 17]. Particle sizes and the 
Fig. $4{ }^{111}$ In-DTPA octreotide for carcinoid tumor localization. a Following an intravenous injection of ${ }^{111}$ In-DTPA octreotide, accumulation in the left side of the liver was seen on the scintigram (arrow). b Fused SPECT/CT and c CT image showing radiotracer uptake in a prehepatic lymph node (color figure online).

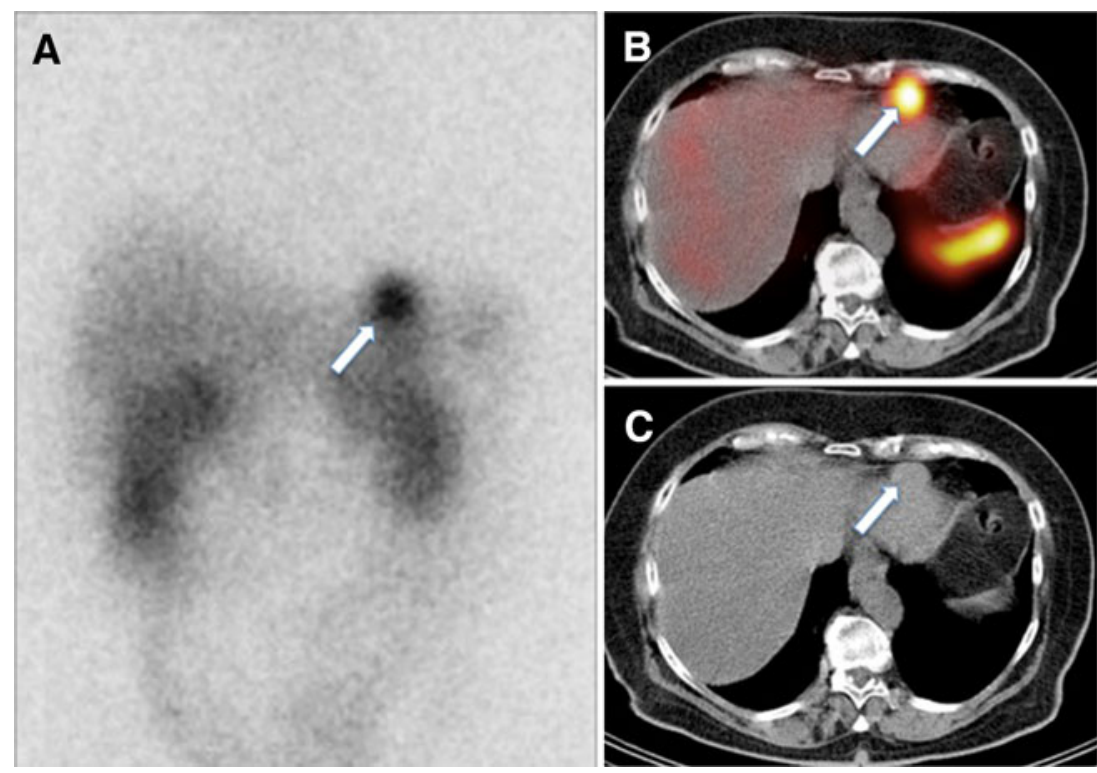

amount/volume of radiocolloid injected influence the lymphatic flow and the overflow of these tracers into higher echelon nodes; accumulation of all these SLN tracers is based on uptake in the macrophages [38]. Recently, a PET derivative was introduced in the form of 89-zirconium $\left({ }^{89} \mathrm{Zr}\right)$-labeled nanocolloid [39].

\section{Timanocept $\left(\right.$ Lymphoseek $\left.^{\circledR}\right)$}

${ }^{99 \mathrm{~m}} \mathrm{Tc}$-tilmanocept was introduced as an alternative to the above-mentioned radiocolloids [40, 41]. ${ }^{99 \mathrm{~m}} \mathrm{Tc}$-tilmanocept is smaller than most radiocolloids (mean molecular diameter of 7 vs. 10-600 nm); it is based on a dextran backbone substituted with multiple mannose subunits and chelates to allow radiolabeling with ${ }^{99 \mathrm{~m}} \mathrm{Tc}$ [42]. It has been suggested that ${ }^{99 \mathrm{~m}}$ Tc-tilmanocept accumulates in the SLNs by binding to mannose receptors on reticuloendocytes [43].

\section{Introduction of (fluorescent) dye guidance to extend radioguided surgery}

Radioguided surgery is an excellent technique for the preoperative localization of a lesion of interest. However, as mentioned above, in the intraoperative setting the limited spatial resolution of this modality is suboptimal for precise (last millimeter) localization. For this part of the resection, an additional tool based on real-time and highresolution imaging (e.g., fluorescence) can be of great benefit.

Blue dye is commonly used to visualize the lymph vessels and the SLN during the surgical act. Motomura et al. [44] were the first to describe the use of the nearinfrared dye ICG for SLN biopsy in breast cancer; ICG was used in a manner similar to blue dye. Thereafter, many different research groups adapted this fluorescence-based approach with ICG for SLN biopsy in different types of cancer, e.g., in melanoma and breast cancer [45, 46]. Fluorescent dyes have a higher tissue penetration compared to conventional blue dye, but unfortunately, the tissue penetration remains limited to approximately $1 \mathrm{~cm}$ [46]. This limitation can be overcome by combining ICG with the high tissue penetration of radioactive agents $[9,47,48]$.

\section{Hybrid-imaging agents}

In 2011, we introduced the clinical application of a hybrid radiolabeled colloid (ICG non-covalently bound to ${ }^{99 \mathrm{~m}} \mathrm{Tc}$ nanocolloid) in prostate cancer patients [49]. With a single injection of this hybrid tracer, we were able to visualize the SLNs both preoperatively, using lymphoscintigraphy and SPECT/CT, and intraoperatively via fluorescence imaging (Fig. 5). The same hybrid tracer has now been used for SLN biopsy in various types of malignancies, e.g., melanoma and penile cancer $[10,47,50]$. This success should encourage further extension of the hybrid approach to surgical areas where there is room for improvement of the RGS technique.

To provide a hybrid derivative for the detection of parathyroid disease, methylene blue has been iodinated with ${ }^{123} \mathrm{I}$ [51]. However, in a clinical study, this tracer was not found to be effective enough to replaces the standard tracer ${ }^{99 \mathrm{~m}}$ Tc-MIBI [52]. Methylene blue labeled with ${ }^{125} \mathrm{I}$ has instead been evaluated for SLN biopsy in a clinical trial in breast cancer [10]. The solution of ${ }^{125}$ I-methylene blue are injected locally in or around the tumor, after which it was transported by the lymphatic system to the SLN. With a hand-held gamma camera, the gamma rays were detected 

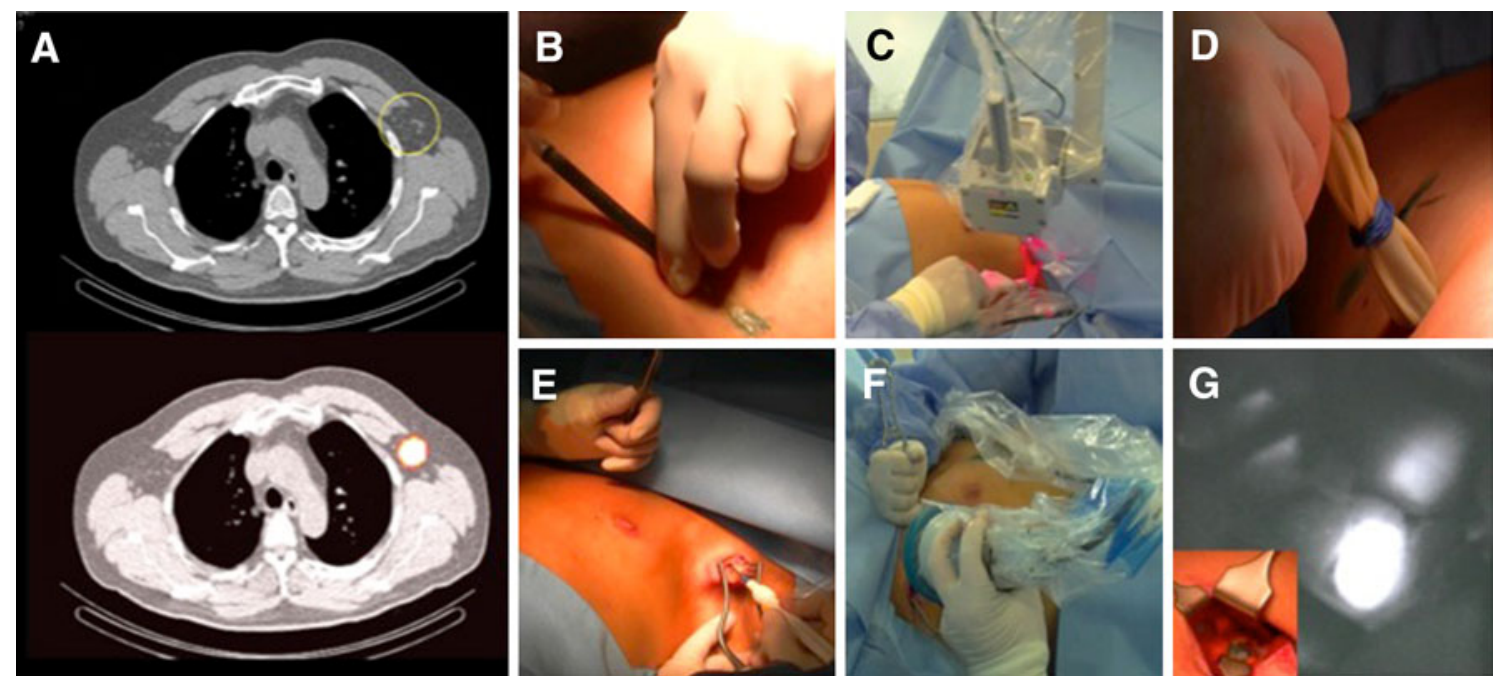

Fig. 5 Multimodal surgical guidance towards the sentinel lymph node. a Following ICG ${ }^{-99 \mathrm{~m}} \mathrm{Tc}$-nanocolloid injection, preoperative lymphoscinitigraphy and SPECT/CT imaging are performed to locate the SLN (circle). b Prior to the start of the operation patent blue dye is injected. $\mathbf{c}$ Prior to incision, an image with gamma camera is obtained

and the blue signature of methylene blue was used to optically identify the SLN. Rapid lymphatic drainage of the hybrid tracer is a possible downside of this approach.

In the preclinical setting, a great number of hybrid alternatives to existing RGS tracers are currently being developed and evaluated (Table 1). For example, ${ }^{99 \mathrm{~m}} \mathrm{Tc}-$ tilmanocept has been covalently labeled with $\mathrm{Cy} 7$ for fluorescence imaging. In a mouse model it was shown that the popliteal SLN could be visualized with fluorescence imaging following a footpad injection with $\mathrm{Cy} 7{ }^{99 \mathrm{~m}} \mathrm{Tc}-$ tilmanocept [53].

Multimodal marker seeds have been shown to allow hybrid RSL towards a mouse prostate [54]. Here, the ${ }^{99 \mathrm{~m}} \mathrm{Tc}$ signature allowed preoperative SPECT imaging, whereas intraoperative fluorescence detection provided optical information about the exact location of the seed [54].

\section{Targeted hybrid-imaging agents}

Research efforts are currently focusing on the development of targeted hybrid tracers allowing accurate tumor identification. Despite these efforts, which have been reviewed by Kuil et al. [8] and Azhdarinia et al. [55], to date no such tracers have been clinically implemented.

Hybrid-labeled derivatives of the clinically applied octreotide have been extensively evaluated preclinically, yielding fluorescent and radioactively labeled imaging agents with high affinity for the somatostatin receptor [8, 56]. Alongside these hybrid counterparts of clinically used peptide-based tracers, several other interesting hybrid tracers are being developed, based, for example, on tumor- to confirm the localization of the SLN. d Pre-incision gamma tracing with the gamma probe allows localization of the SLN. e Incision. f Camera used to detect the fluorescent signal in the SLN. g Fluorescence signal detected in the SLN. SLN sentinel lymph node (color figure online)

targeting peptides targeting the chemokine receptor 4 and the gastric releasing peptide receptor [8]. A hybrid tracer targeting the prostate-specific membrane antigen (PSMA), which is frequently overexpressed in prostate cancer, was recently developed by Banerjee et al. [57] by combining the near-infrared dye CW800 and ${ }^{111}$ In-1,4,7,10-tetraazycyclododecane-1,4,7,10-tetracarboxylic acid (DOTA) with a PSMA-inhibitor.

Multiple hybrid tracers have been generated for $\alpha_{\mathrm{v}} \beta_{3^{-}}$ integrin, which is overexpressed by activated endothelial cells during angiogenesis. These hybrid tracers contain a Cy5- or Cy7-derivative as fluorescent dye and a DTPA, deferoxamine or DOTA chelate to introduce ${ }^{111} \mathrm{In},{ }^{64} \mathrm{Cu}$ or ${ }^{68} \mathrm{Ga}$, respectively [8]. Liu et al. [58] recently introduced a tracer that combines the fluorescent dye BODIPY, containing ${ }^{18} \mathrm{~F}$, with the cyclic arginine-glycine-aspartate (RGD) peptide targeting the $\alpha_{\mathrm{v}} \beta_{3}$-integrin for combined PET and optical imaging.

In addition, various hybrid-labeled antibodies have been tested in mouse models [59-62]. ${ }^{64} \mathrm{Cu}-1,4,7$-triazacyclononane-1,4,7-triacetic acid (NOTA)-bevacizumab-800CW was applied to detect human glioblastoma tumors by both nuclear and optical imaging [63]. The anti-CD105 antibody TRC105 was labeled with ${ }^{64} \mathrm{Cu}$ or ${ }^{89} \mathrm{Zr}$ for PET imaging and $800 \mathrm{CW}$ for intraoperative optical fluorescence-based detection in a mouse model of breast cancer-derived lung metastases [64]. Recently, Cohen et al. [65] described a protocol for the labeling of monoclonal antibodies with $800 \mathrm{CW}$ and ${ }^{89} \mathrm{Zr}$ for hybrid imaging. Although not yet used for clinical studies these antibody-based hybrid tracers seem promising for future applications. 
Table 1 Currently used radiotracers and preclinically and clinically used hybrid-imaging agents (color table online)

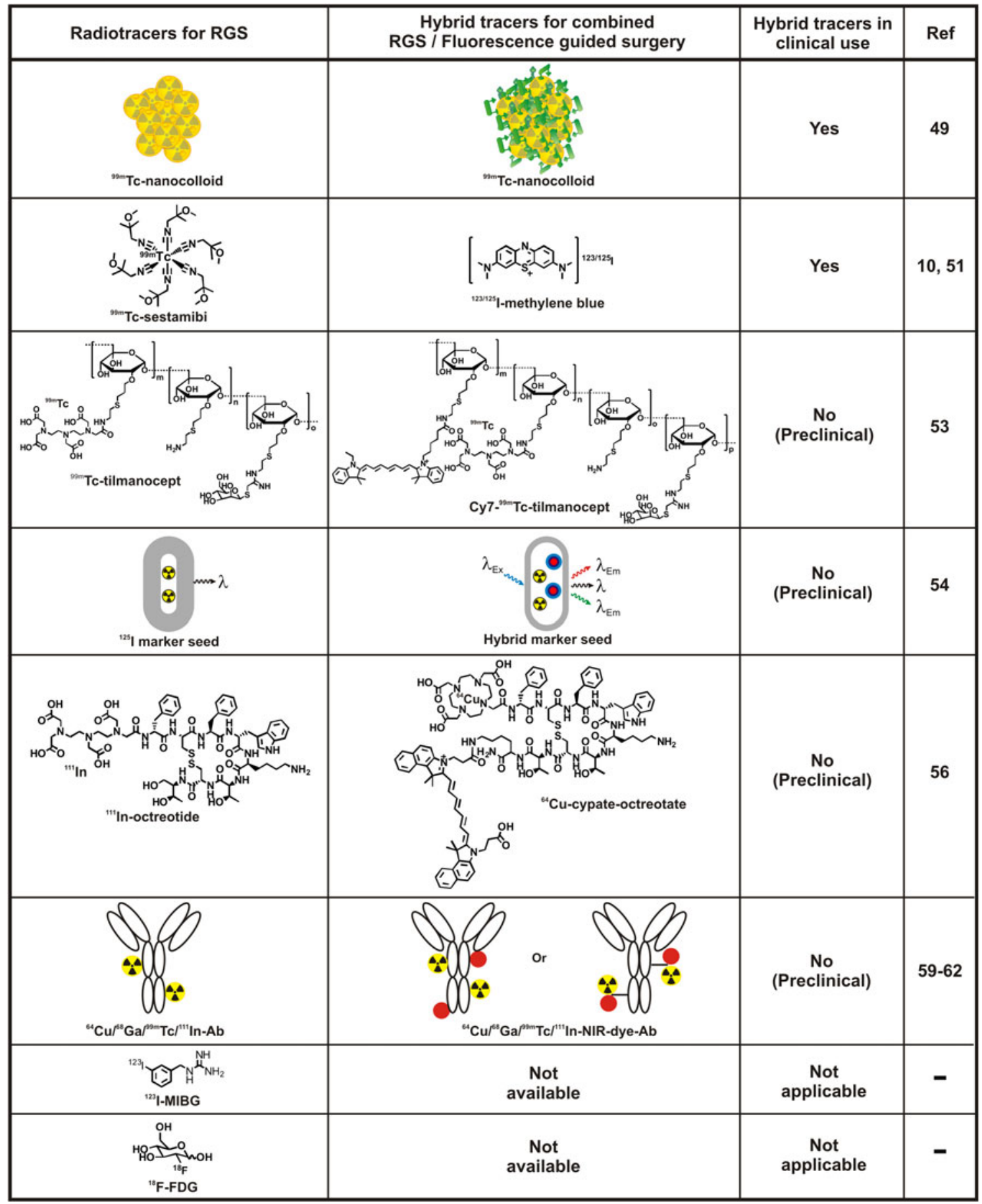

\section{Modalities used during hybrid-radioguided surgery}

Different modalities can be used for the intraoperative localization of the preoperatively injected radiotracers. Devices to locate both gamma- and positron-emitting radioisotopes, as well as devices that can excite fluorescent dyes and collect their emission light, are discussed below.
Ideally, the introduction of a hybrid approach also drives the development of hybrid-imaging devices.

\section{PET detection probes}

Positron emission tomography detection probes are capable of detecting the $511-\mathrm{KeV}$ gamma rays that are emitted by 
the annihilation of a positron-electron pair. Unfortunately, the collimators and shielding used for detection make these probes less convenient during surgery; $511-\mathrm{keV}$ gamma rays are highly penetrating $[36,66,67]$.

Another PET tracer-detection method is direct detection of the $\beta^{+}$-particles (positrons). These particles have limited soft tissue penetration (max. $2.4 \mathrm{~mm}$ ) [68]. As a result, direct positron detection is easily hindered by overlying/ surrounding tissue, similarly to what happens with the use of fluorescent dyes [6]. On the other hand, this property may provide increased resolution, making it possible to distinguish between tumor tissue and healthy tissue [66].

Cerenkov luminescence emitted by $\beta$-emitters can also potentially be used for intraoperative optical detection and might be an alternative to hybrid agents with a fluorescent dye [69]. That said, Chin et al. [6] concluded that with the current imaging modalities, the fluorescent signature of a hybrid tracer is superior to Cerenkov luminescence.

\section{Gamma probes}

Gamma probes can be used to locate different isotopes with low, medium and high energies. The technical features and capabilities of common gamma probes have been reviewed by Zanzonico and Heller [66, 70]. In these reviews they also discuss the capabilities of the gamma probes.

With gamma probes, it is sometimes difficult to locate areas of interest near the injection site, because the signal can be masked by background 'signal bleeding' [71]. As hybrid radioactive and fluorescent imaging agents emerge, a possible future development would be a gamma probe that is also capable of (acoustic) fluorescence detection. Hybrid-imaging devices can be obtained either by modifying existing RGS devices or fluorescence cameras or by developing new imaging devices. Although it is not yet available for fluorescence imaging, there does exist a system that allows acoustic gamma tracing and acoustic blue dye tracing (Eurorad, Strasbourg, France). A gamma probe that can also detect fluorescence could be used to determine margins intraoperatively, overcoming the limited tissue penetration of near-infrared dyes.

\section{Gamma cameras}

While a gamma probe provides an acoustic signal when it detects gamma rays, a gamma camera allows the generation of $2 \mathrm{D}$ visual images of the location of the radioactive signal [36]. Compared to gamma probes, mobile gamma cameras show improved imaging resolution [66]. Several hand-held and mobile gamma cameras are described in a review by Tsuchimochi and Hayama [36]. The main advantage of a mobile gamma camera is that it allows reproduction, in the operating room, of preoperatively acquired images. Moreover, by generating pre-incision and post-excision images, a comparison can be made to determine whether there is any residual activity at the excision site, which should also be removed.

A disadvantage of gamma cameras is the delay in visualization of hot spots, which results in long acquisition times in the presence of a weak radioactive signal in the lesion of interest. Moreover, since the current systems do not provide 'white light' options to visualize the surgical field, there is a lack of anatomical information of the area of interest. Furthermore, the current gamma camera systems do not usually provide depth information.

A promising development for gamma cameras may therefore be their integration with optical cameras to provide visualization of radioactive hot spots within the corresponding anatomical context. Blake et al. [72] published data relating to the application of a prototype mini-gamma camera integrated with an optical camera: the first results in patients injected with ${ }^{99 \mathrm{~m}} \mathrm{Tc}$-hydroxymethylene diphosphate for a standard bone scan showed accumulation of the activity in the thumb.

A next step may be the integration of fluorescence cameras. In combination with the right hybrid tracer, devices of this kind would be capable of hybrid surgical guidance using a single modality.

\section{Intraoperative navigation devices}

The simplest example of navigation uses a mobile gamma camera that allows dual-isotope detection, as shown by Vermeeren et al. [73] during laparoscopic SLN biopsy in prostate cancer. After a ${ }^{125}$ I-seed had been attached to the tip of a laparoscopic gamma probe, its location could be detected on screen together with the signal coming from ${ }^{99 \mathrm{~m}} \mathrm{Tc}$ in the SLN. By moving the gamma probe towards the SLN, the signal from the ${ }^{125}$ I-seed could be followed on the gamma probe, providing on-screen $2 \mathrm{D}$ navigation to the SLN [74].

The introduction of freehand SPECT technology has made it possible for surgeons to intraoperatively acquire a SPECT scan of a region of interest. By tracking both the gamma probe and a positioning system fixed on the patient's body, this technique allows intraoperative 3D mixed reality-based navigation of the gamma probe to the lesion of interest, e.g., during SLN biopsy for breast cancer [75]. As well as allowing real-time acquisition of SPECT scans in the operating room, the system can also load preoperatively acquired SPECT/CT data. It has been shown that this approach can also be used to navigate tools other than the gamma probe, e.g., a fluorescence laparoscope, towards radioactive hotspots [76]. Fluoresence imaging allows errors within the $1-\mathrm{cm}$ range (due to organ movement or deformation for example) to be compensated for [76]. 
With the exception of a navigation system that uses virtual reality to visualize the radioactive hot spots in the anatomical context, the current RGS techniques do not provide anatomical information [77]. An additional tool that combines the beneficial properties of both modalities would be of great value in this field of surgery.

\section{Conclusion}

The applications of RGS are continuously expanding as new receptor-targeted imaging agents and intraoperative tools emerge. Since radio- and fluorescence-based surgical guidance modalities each have their own beneficial properties, the development of hybrid approaches, which combine advantageous features of both techniques, holds great promise for the further refinement of RGS.

Acknowledgments This work was partially supported by a Dutch Cancer Society translational research award (Grant No. PGF 2009-4344), an NWO-STW-VIDI grant (Grant No. STW BGT11272), and an ERC-starting grant (Grant No. 2012-306890).

Conflict of interest The authors declare that they have no conflicts of interest.

Human and Animal Studies This article does not contain any studies with human or animal subjects performed by any of the authors.

\section{References}

1. Povoski SP, Neff RL, Mojzisik CM, O’Malley DM, Hinkle GH, Hall NC, Murrey D, Knopp MV, Martin EW (2009) A comprehensive overview of radioguided surgery using gamma detection probe technology. World J Surg Oncol 7:11

2. Goorden MC, Van der Have F, Kreuger R, Ramakers RM, Vastenhouw B, Burbach JPH, Booij J, Molthoff CFM, Beekman FJ (2013) VECTor: a preclinical imaging system for simultaneous submillimeter SPECT and PET. J Nucl Med 54:306-312

3. Morton DL, Wen DR, Wong JH, Economou JS, Cagle LA, Storm FK, Foshag LJ, Cochran AJ (1992) Technical details of intraoperative lymphatic mapping for early stage melanoma. Arch Surg 127:392-399

4. Nieweg OE, Tanis PJ, Kroon BB (2001) The definition of a sentinel node. Ann Surg Oncol 8:538-541

5. Van den Berg NS, Van Leeuwen FWB, Van der Poel HG (2012) Fluorescence guidance in urologic surgery. Curr Opin Urol 22:109-120

6. Chin PTK, Welling MM, Meskers SCJ, Valdes Olmos RA, Tanke H, Van Leeuwen FWB (2013) Optical imaging as an expansion of nuclear medicine: Cerenkov-based luminescence vs. fluorescence-based luminescence. Eur J Nucl Med Mol Imaging 40:1283-1291

7. Buckle T, Van Leeuwen AC, Chin PTK, Janssen H, Muller SH, Jonkers J, Van Leeuwen FWB (2010) A self-assembled multimodal complex for combined pre- and intraoperative imaging of the sentinel lymph node. Nanotechnology 3(21):355101
8. Kuil J, Velders AH, Van Leeuwen FWB (2010) Multimodal tumor-targeting peptides functionalized with both a radio- and a fluorescent label. Bioconjug Chem 21:1709-1719

9. Brouwer OR, Buckle T, Vermeeren L, Klop WMC, Balm AJM, Van der Poel HG, Van Rhijn BW, Horenblas S, Nieweg OE, Van Leeuwen FWB, Valdés Olmos RA (2012) Comparing the hybrid fluorescent-radioactive tracer indocyanine green- ${ }^{99 \mathrm{~m}} \mathrm{Tc}$-nanocolloid with ${ }^{99 \mathrm{~m}} \mathrm{Tc}$-nanocolloid for sentinel node identification: a validation study using lymphoscintigraphy and SPECT/CT. J Nucl Med 53:1034-1040

10. Harkrider WW, Diebold AE, Maloney T, Espenan G, Wang YZ, Stafford SJ, Camp A, Frey D, Chappuis C, Woltering EA (2013) An extended phase II trial of iodine-125 methylene blue for sentinel lymph node identification in women with breast cancer. J Am Coll Surg 216:599-605 (discussion 605-606)

11. Duarte GM, Cabello C, Torresan RZ, Alvarenga M, Telles GHC, Bianchessi ST, Caserta N, Segala SR, de Lima MCL, Etchebehere ECSC, Camargo EE (2007) Radioguided intraoperative margins evaluation (RIME): preliminary results of a new technique to aid breast cancer resection. Eur J Surg Oncol 33:1150-1157

12. Mery CM, Shafi BM, Binyamin G (2006) Molecular imaging and radioimmunoguided surgery. Semin Pediatr Surg 15:259-266

13. Arnold M, Schneebaum S, Martin E (1996) Radioimmunoguided surgery in the treatment and evaluation of rectal cancer patients. Cancer Control 3:42-45

14. Uren RF, Howman-Giles RB, Shaw HM, Thompson JF, McCarthy WH (1993) Lymphoscintigraphy in high-risk melanoma of the trunk: predicting draining node groups, defining lymphatic channels and locating the sentinel node. J Nucl Med 34:1435-1440

15. Van Riet YEA, Maaskant AJG, Creemers GJ, van Warmerdam LJC, Jansen FH, van de Velde CJH, Rutten HJT, Nieuwenhuijzen GAP (2010) Identification of residual breast tumour localization after neo-adjuvant chemotherapy using a radioactive 125 Iodine seed. Eur J Surg Oncol 36:164-169

16. Alderliesten T, Loo CE, Pengel KE, Rutgers EJT, Gilhuijs KGA, Vrancken Peeters MJ (2011) Radioactive seed localization of breast lesions: an adequate localization method without seed migration. Breast J 17:594-601

17. Donker M, Straver ME, Rutgers EJTh, Valdés Olmos RA, Loo CE, Sonke GS, Wesseling J, Vrancken Peeters MJ (2012) Radioguided occult lesion localisation (ROLL) in breast-conserving surgery after neoadjuvant chemotherapy. Eur J Surg Oncol 38:1218-1224

18. Donker M, Drukker CA, Valdés Olmos RA, Rutgers EJTh, Loo CE, Sonke GS, Wesseling J, Alderliesten T, Vrancken Peeters MJ (2013) Guiding breast-conserving surgery in patients after neoadjuvant systemic therapy for breast cancer: a comparison of radioactive seed localization with the ROLL technique. Ann Surg Oncol 20:2569-2575

19. Thind CR, Tan S, Desmond S, Harris O, Ramesh HSJ, Chagla L, Ray A, Audisio R (2011) SNOLL. sentinel node and occult (impalpable) lesion localization in breast cancer. Clin Radiol 66:833-839

20. Ahmed M, Douek M (2013) ROLL versus RSL: toss of a coin? Breast Cancer Res Treat 140:213-217

21. Roach M III, Alberini JL, Pecking AP, Testori A, Verrecchia F, Soteldo J, Ganswindt U, Joyal JL, Babich JW, Witte RS, Unger E, Gottlieb R (2011) Diagnostic and therapeutic imaging for cancer: therapeutic considerations and future directions. J Surg Oncol 103:587-601

22. Sun D, Bloomston M, Hinkle G, Al-Saif OH, Hall NC, Povoski SP, Arnold MW, Martin EW Jr (2007) Radioimmunoguided surgery (RIGS), PET/CT image-guided surgery, and fluorescence 
image-guided surgery: past, present, and future. J Surg Oncol 15(96):297-308

23. Povoski SP, Hall NC, Murrey DA Jr, Sharp DS, Hitchcock CL, Mojzisik CM, Bahnson EE, Knopp MV, Martin EW Jr, Bahnson RR (2013) Multimodal imaging and detection strategy with 124 I-labeled chimeric monoclonal antibody cG250 for accurate localization and confirmation of extent of disease during laparoscopic and open surgical resection of clear cell renal cell carcinoma. Surg Innov 20:59-69

24. Scollard DA, Chan C, Holloway CM, Reilly RM (2011) A kit to prepare ${ }^{111}$ In-DTPA-trastuzumab (Herceptin) Fab fragments injection under GMP conditions for imaging or radioimmunoguided surgery of HER2-positive breast cancer. Nucl Med Biol 38:129-136

25. Francis CL, Nalley C, Fan C, Bodenner D, Stack BC Jr (2012) 18F-fluorodeoxyglucose and 131I radioguided surgical management of thyroid cancer. Otolaryngol Head Neck Surg 146:26-32

26. Tunca F, Giles Y, Terzioglu T, Mudun A, Adalet I, Salmaslioglu A, Tezelman S (2008) Does intraoperative radioguided surgery influence the complication rates and completeness of completion thyroidectomy? Am J Surg 196:40-46

27. Ikeda Y, Takayama J, Takami H (2010) Minimally invasive radioguided parathyroidectomy for hyperparathyroidism. Ann Nucl Med 24:233-240

28. Hetrakul N, Civelek AC, Stagg CA, Udelsman R (2001) In vitro accumulation of technetium-99m-sestamibi in human parathyroid mitochondria. Surgery 130:1011-1018

29. Norman JG, Jaffray CE, Chheda H (2000) The false-positive parathyroid sestamibi: a real or perceived problem and a case for radioguided parathyroidectomy. Ann Surg 231:31-37

30. Negele T, Meisetschläger G, Brückner T, Scheidhauer K, Schwaiger M, Vogelsang H (2006) Radio-guided surgery for persistent differentiated papillary thyroid cancer: case presentations and review of the literature. Langenbecks Arch Surg 391:178-186

31. van Hulsteijn LT, Corssmit EP, van der Hiel B, Smit JW, Stokkel MP (2012) Is there a role for radioguided surgery with iodinelabeled metaiodobenzylguanidine in resection of neuroendocrine tumors? Clin Nucl Med 37:1083-1088

32. Wang YZ, Diebold A, Woltering E, King H, Boudreaux JP, Anthony LB, Campeau R (2011) Radioguided exploration facilitates surgical cytoreduction of neuroendocrine tumors. J Gastrointest Surg 16:635-640

33. Keskin O, Yalcin S (2013) A review of the use of somatostatin analogs in oncology. Onco Targets Ther 6:471-483

34. Porziella V, Cesario A, Lococo F, Cafarotti S, Margaritora S, D'Errico G, Granone P (2011) The radioguided ${ }^{111}$ In-pentetreotide surgery in the management of ACTH-secreting bronchial carcinoid. Eur Rev Med Pharmacol Sci 15:587-591

35. Pinilla I, Rodríguez-Vigil B, Gómez-León N (2008) Integrated FDG PET/CT: utility and applications in clinical oncology. Clin Med Oncol 2:181-198

36. Tsuchimochi M, Hayama K (2013) Intraoperative gamma cameras for radioguided surgery: technical characteristics, performance parameters, and clinical applications. Phys Med 29:126-138

37. Wilhelm AJ, Mijnhout GS, Franssen EJ (1999) Radiopharmaceuticals in sentinel lymph-node detection-an overview. Eur $\mathbf{J}$ Nucl Med 26(4 Suppl):S36-S42

38. Uren RF, Howman-Giles R, Thompson JF (2003) Patterns of lymphatic drainage from the skin in patients with melanoma. J Nucl Med 44:570-582

39. Heuveling DA, van Schie A, Vugts DJ, Hendrikse NH, Yaqub M, Hoekstra OS, Karagozoglu KH, Leemans CR, van Dongen GA, de Bree R (2013) Pilot study on the feasibility of PET/CT lymphoscintigraphy with ${ }^{89} \mathrm{Zr}$-nanocolloidal albumin for sentinel node identification in oral cancer patients. J Nucl Med 54:585-589
40. Wallace AM, Han LK, Povoski SP, Deck K, Schneebaum S, Hall NC, Hoh CK, Limmer KK, Krontiras H, Frazier TG, Cox C, Avisar E, Faries M, King DW, Christman L, Vera DR (2013) Comparative evaluation of $\left[{ }^{99 \mathrm{~m}} \mathrm{Tc}\right]$ tilmanocept for sentinel lymph node mapping in breast cancer patients: results of two phase 3 trials. Ann Surg Oncol 20:2590-2599

41. Sondak VK, King DW, Zager JS, Schneebaum S, Kim J, Leong SP, Faries MB, Averbook BJ, Martinez SR, Puleo CA, Messina JL, Christman L, Wallace AM (2013) Combined analysis of phase III trials evaluating [ $\left.{ }^{99 \mathrm{~m}} \mathrm{Tc}\right]$ tilmanocept and vital blue dye for identification of sentinel lymph nodes in clinically nodenegative cutaneous melanoma. Ann Surg Oncol 20:680-688

42. Vera DR, Wallace AM, Hoh CK, Mattrey RF (2001) A synthetic macromolecule for sentinel node detection: ${ }^{99 \mathrm{~m}} \mathrm{Tc}-\mathrm{DTPA}-\mathrm{man}-$ nosyl-dextran. J Nucl Med 42:951-959

43. Tokin CA, Cope FO, Metz WL, Blue MS, Potter BM, Abbruzzese BC, Hartman RD, Joy MT, King DW, Christman LA, Vera DR, Wallace AM (2012) The efficacy of Tilmanocept in sentinel lymph mode mapping and identification in breast cancer patients: a comparative review and meta-analysis of the ${ }^{99 \mathrm{~m}}$ Tc-labeled nanocolloid human serum albumin standard of care. Clin Exp Metastasis 29:681-686

44. Motomura K, Inaji H, Komoike Y, Kasugai T, Noguchi S, Koyama H (1999) Sentinel node biopsy guided by indocyanine green dye in breast cancer patients. Jpn J Clin Oncol 29:604-607

45. Schaafsma BE, Mieog JS, Hutteman M, van der Vorst JR, Kuppen PJ, Löwik CW, Frangioni JV, van de Velde CJ, Vahrmeijer AL (2011) The clinical use of indocyanine green as a nearinfrared fluorescent contrast agent for image-guided oncologic surgery. J Surg Oncol 104:323-332

46. Polom K, Murawa D, Rho YS, Nowaczyk P, Hünerbein M, Murawa P (2011) Current trends and emerging future of indocyanine green usage in surgery and oncology: a literature review. Cancer 117:4812-4822

47. Brouwer OR, Klop WMC, Buckle T, Vermeeren L, van den Brekel MWM, Balm AJM, Nieweg OE, Valdés Olmos RA, van Leeuwen FWB (2012) Feasibility of sentinel node biopsy in head and neck melanoma using a hybrid radioactive and fluorescent tracer. Ann Surg Oncol 19:1988-1994

48. van den Berg NS, Brouwer OR, Klop WM, Karakullukcu B, Zuur CL, Tan IB, Balm AJ, van den Brekel MW, Valdés Olmos RA, van Leeuwen FW (2012) Concomitant radio- and fluorescenceguided sentinel lymph node biopsy in squamous cell carcinoma of the oral cavity using ICG- ${ }^{99 \mathrm{~m}}$ Tc-nanocolloid. Eur J Nucl Med Mol Imaging 39:1128-1136

49. van der Poel HG, Buckle T, Brouwer OR, Valdés Olmos RA, van Leeuwen FW (2011) Intraoperative laparoscopic fluorescence guidance to the sentinel lymph node in prostate cancer patients: clinical proof of concept of an integrated functional imaging approach using a multimodal tracer. Eur Urol 60:826-833

50. Schaafsma BE, Verbeek FP, Rietbergen DD, van der Hiel B, van der Vorst JR, Liefers GJ, Frangioni JV, van de Velde CJ, van Leeuwen FW, Vahrmeijer AL (2013) Clinical trial of combined radio- and fluorescence-guided sentinel lymph node biopsy in breast cancer. Br J Surg 100:1037-1044

51. Blower PJ, Carter NJ (1990) Rapid preparation of ${ }^{123}$ I-labelled methylene blue and toluidine blue: potential new agents for parathyroid scintigraphy. Nucl Med Commun 11:413-420

52. Blower PJ, Kettle AG, O’Doherty MJ, Collins RE, Coakley AJ (1992) ${ }^{123}$ I-methylene blue: an unsatisfactory parathyroid imaging agent. Nucl Med Commun 13:522-527

53. Emerson DK, Limmer KK, Hall DJ, Han SH, Eckelman WC, Kane CJ, Wallace AM, Vera DR (2012) A receptor-targeted fluorescent radiopharmaceutical for multireporter sentinel lymph node imaging. Radiology 265:186-193 
54. Buckle T, Chin PT, van den Berg NS, Loo CE, Koops W, Gilhuijs KG, van Leeuwen FWB (2010) Tumor bracketing and safety margin estimation using multimodal marker seeds: a proof of concept. J Biomed Opt 15:056021

55. Azhdarinia A, Ghosh P, Ghosh S, Wilganowski N, Sevick-Muraca EM (2012) Dual-labeling strategies for nuclear and fluorescence molecular imaging: a review and analysis. Mol Imaging Biol 14:261-276

56. Edwards WB, Xu B, Akers W, Cheney PP, Liang K, Rogers BE, Anderson CJ, Achilefu S (2008) Agonist-antagonist dilemma in molecular imaging: evaluation of a monomolecular multimodal imaging agent for the somatostatin receptor. Bioconjug Chem 19:192-200

57. Banerjee SR, Pullambhatla M, Byun Y, Nimmagadda S, Foss CA, Green G, Fox JJ, Lupold SE, Mease RC, Pomper MG (2011) Sequential SPECT and optical imaging of experimental models of prostate cancer with a dual modality inhibitor of the prostate-specific membrane antigen. Angew Chem Int Ed Engl 50:9167-9170

58. Liu S, Lin TP, Li D, Leamer L, Shan H, Li Z, Gabbaï FP, Conti PS (2013) Lewis acid-assisted isotopic ${ }^{18} \mathrm{~F}-{ }^{19} \mathrm{~F}$ exchange in BODIPY dyes: facile generation of positron emission tomography/fluorescence dual modality agents for tumor imaging. Theranostics 3:181-199

59. Ghosh SC, Ghosh P, Wilganowski N, Robinson H, Hall MA, Dickinson G, Pinkston KL, Harvey BR, Sevick-Muraca EM, Azhdarinia A (2013) Multimodal chelation platform for nearinfrared fluorescence/nuclear imaging. J Med Chem 56:406-416

60. Zhang Y, Hong H, Engle JW, Yang Y, Theuer CP, Barnhart TE, Cai W (2012) Positron emission tomography and optical imaging of tumor CD105 expression with a dual-labeled monoclonal antibody. Mol Pharm 9:645-653

61. Zhang Y, Hong H, Engle JW, Yang Y, Theuer CP, Barnhart TE, Cai W (2012) Multimodality imaging of breast cancer experimental lung metastasis with bioluminescence and a monoclonal antibody dual-labeled with ${ }^{89} \mathrm{Zr}$ and IRDye $800 \mathrm{CW}$. Mol Pharm 9:645-653

62. Sevick-Muraca EM (2012) Translation of near-infrared fluorescence imaging technologies: emerging clinical applications. Annu Rev Med 63:217-231

63. Zhang Y, Hong H, Engle JW, Yang Y, Barnhart TE, Cai W (2012) Positron emission tomography and near-infrared fluorescence imaging of vascular endothelial growth factor with duallabeled bevacizumab. Am J Nucl Med Mol Imaging 2:1-13

64. Zhang Y, Hong H, Nayak TR, Valdovinos HF, Myklejord DV, Theuer CP, Barnhart TE, Cai W (2013) Imaging tumor angiogenesis in breast cancer experimental lung metastasis with positron emission tomography, near-infrared fluorescence, and bioluminescence. Angiogenesis 16:663-674
65. Cohen R, Vugts DJ, Stigter-van Walsum M, Visser GW, van Dongen GA (2013) Inert coupling of IRDye800CW and zirconium-89 to monoclonal antibodies for single- or dual-mode fluorescence and PET imaging. Nat Protoc 8:1010-1018

66. Heller S, Zanzonico P (2011) Nuclear probes and intraoperative gamma cameras. Semin Nucl Med 41:166-181

67. Gulec SA (2007) PET probe-guided surgery. J Surg Oncol 96:353-357

68. Piert M, Burian M, Meisetschläger G, Stein HJ, Ziegler S, Nährig J, Picchio M, Buck A, Siewert JR, Schwaiger M (2007) Positron detection for the intraoperative localisation of cancer deposits. Eur J Nucl Med Mol Imaging 34:1534-1544

69. Thorek DL, Abou DS, Beattie BJ, Bartlett RM, Huang R, Zanzonico PB, Grimm J (2012) Positron lymphography: multimodal, high-resolution, dynamic mapping and resection of lymph nodes after intradermal injection of ${ }^{18}$ F-FDG. J Nucl Med 53:1438-1445

70. Zanzonico P, Heller S (2000) The intraoperative gamma probe: basic principles and choices available. Semin Nucl Med 30:33-48

71. Bricou A, Duval MA, Charon Y, Barranger E (2013) Mobile gamma cameras in breast cancer care: a review. Eur J Surg Oncol 39:409-416

72. Lees JE, Bassford DJ, Blake OE, Blackshaw PE, Perkins AC (2012) Hybrid camera for simultaneous imaging of gamma and optical photons. JINST 7:P06009

73. Vermeeren L, Meinhardt W, van der Poel HG, Valdés Olmos RA (2010) Lymphatic drainage from the treated versus untreated prostate: feasibility of sentinel node biopsy in recurrent cancer. Eur J Nucl Med Mol Imaging 37:2021-2026

74. Olmos RA, Vidal-Sicart S, Nieweg OE (2009) SPECT-CT and real-time intraoperative imaging: new tools for sentinel node localization and radioguided surgery? Eur J Nucl Med Mol Imaging 36:1-5

75. Okur A, Ahmadi SA, Bigdelou A, Wendler T, Navab N (2011) MR in OR: first analysis of AR/VR visualization in 100 intraoperative Freehand SPECT acquisitions. In: 10th IEEE international symposium on mixed and augmented reality, pp 211-218

76. Brouwer OR, Buckle T, Bunschoten A, Kuil J, Vahrmeijer AL, Wendler T, Valdés-Olmos RA, van der Poel HG, van Leeuwen FW (2012) Image navigation as a means to expand the boundaries of fluorescence-guided surgery. Phys Med Biol 57:3123-3136

77. Wendler T, Herrmann K, Schnelzer A, Lasser T, Traub J, Kutter O, Ehlerding A, Scheidhauer K, Schuster T, Kiechle M, Schwaiger M, Navab N, Ziegler SI, Buck AK (2010) First demonstration of 3-D lymphatic mapping in breast cancer using freehand SPECT. Eur J Nucl Med Mol Imaging 37:1452-1461 